\title{
Causes of delay and cost overrun in Malaysian construction industry
}

\begin{abstract}
The construction industry in Malaysia drives the economic growth and development of the country. However, the industry is plagued with delays and cost overrun which transforms what should have been successful projects to projects incurring additional costs, disagreements, litigation and in some cases abandonment of projects. This research studied the causes of delays and cost overrun in the industry and ranked them according to their perceived importance to the contractors, with a view to establishing those to be addressed by the contractors. Online questionnaires were used for data collection for this research. A total of 69 responses were analysed using principal component analysis (PCA) (factor analysis) to identify the main causes. The result of the analysis showed that delay in preparation of design document, poor schedule and control of time, delay in delivery of material to site, lack of knowledge about the different defined execution methods, shortage of labour and material in market, and changes in scope of work were the main causes of delay and cost overrun. The identified causes if properly addressed would reduce the rate of delays and cost overrun in construction projects, thus enhancing the economic growth and development of the country.
\end{abstract}

Keyword: Cost overrun; Construction industry; Delays 